\title{
Analysis of geostationary satellite-derived cloud parameters associated with environments with high ice water content
}

\author{
Adrianus de Laat ${ }^{1}$, Eric Defer ${ }^{2}$, Julien Delanoë ${ }^{3}$, Fabien Dezitter ${ }^{4}$, Amanda Gounou $^{5}$, Alice Grandin ${ }^{4}$, \\ Anthony Guignard ${ }^{3}$, Jan Fokke Meirink ${ }^{1}$, Jean-Marc Moisselin ${ }^{5}$, and Frédéric Parol ${ }^{6}$ \\ ${ }^{1}$ KNMI, de Bilt, the Netherlands \\ ${ }^{2}$ Laboratoire d'Aérology, CNRS/OMP Toulouse, France \\ ${ }^{3}$ Laboratoire Atmosphère, Milieux et Observations Spatiales, UVSQ, Guyancourt, France \\ ${ }^{4}$ AIRBUS, Toulouse, France \\ ${ }^{5}$ Météo France, Toulouse, France \\ ${ }^{6}$ Laboratoire d'Optique Atmosphérique, Université de Lille, Sciences et Technologies, Villeneuve d'Ascq, France \\ Correspondence to: Adrianus de Laat (laatdej@knmi.nl)
}

Received: 27 July 2016 - Discussion started: 25 October 2016

Revised: 8 March 2017 - Accepted: 12 March 2017 - Published: 10 April 2017

\begin{abstract}
We present an evaluation of the ability of passive broadband geostationary satellite measurements to detect high ice water content (IWC $>1 \mathrm{~g} \mathrm{~m}^{-3}$ ) as part of the European High Altitude Ice Crystals (HAIC) project for detection of upper-atmospheric high IWC, which can be a hazard for aviation. We developed a high IWC mask based on measurements of cloud properties using the Cloud Physical Properties (CPP) algorithm applied to the geostationary Meteosat Second Generation (MSG) Spinning Enhanced Visible and Infrared Imager (SEVIRI).

Evaluation of the high IWC mask with satellite measurements of active remote sensors of cloud properties (CLOUDSAT/CALIPSO combined in the DARDAR (raDAR-liDAR) product) reveals that the high IWC mask is capable of detecting high IWC values $>1 \mathrm{~g} \mathrm{~m}^{-3}$ in the DARDAR profiles with a probability of detection of $60-80 \%$. The best CPP predictors of high IWC were the condensed water path, cloud optical thickness, cloud phase, and cloud top height. The evaluation of the high IWC mask against DARDAR provided indications that the MSG-CPP high IWC mask is more sensitive to cloud ice or cloud water in the upper part of the cloud, which is relevant for aviation purposes. Biases in the CPP results were also identified, in particular a solar zenith angle (SZA) dependence that reduces the performance of the high IWC mask for SZAs $>60^{\circ}$. Verification statistics show that for the detection of high IWC a trade-off has to be made between better detection of high IWC scenes and more false
\end{abstract}

detections, i.e., scenes identified by the high IWC mask that do not contain IWC $>1 \mathrm{~g} \mathrm{~m}^{-3}$. However, the large majority of these detections still contain IWC values between 0.1 and $1 \mathrm{~g} \mathrm{~m}^{-3}$.

Comparison of the high IWC mask against results from the Rapidly Developing Thunderstorm (RDT) algorithm applied to the same geostationary SEVIRI data showed that there are similarities and differences with the high IWC mask: the RDT algorithm is very capable of detecting young/new convective cells and areas, whereas the high IWC mask appears to be better capable of detecting more mature and ageing convection as well as cirrus remnants.

The lack of detailed understanding of what causes aviation hazards related to high IWC, as well as the lack of clearly defined user requirements, hampers further tuning of the high IWC mask. Future evaluation of the high IWC mask against field campaign data, as well as obtaining user feedback and user requirements from the aviation industry, should provide more information on the performance of the MSG-CPP high IWC mask and contribute to improving the practical use of the high IWC mask.

\section{Introduction}

Weather hazards can not only have a significant impact on aviation by disturbing flight schedules and causing air traffic 
delays but also cause accidents, some of them fatal. Among the weather-related effects on aviation are changes in visibility like fog, clouds, rain, snow, hail, wind, turbulence, lightning, smoke, and volcanic ash (Perkins et al., 1998; Bragg et al., 2002; Mecikalski et al., 2007). One particular hazardous process is in-flight or in-service icing. Aircraft may penetrate clouds of supercooled water droplets, or high densities of ice particles. The droplets or particles then may deposit on cold aircraft surfaces, affecting aerodynamic properties of the plane, the engine performance, or inlets and nozzles used for onboard monitoring of environmental conditions, the latter potentially leading to malfunctioning of, for example, speed sensors (Mason et al., 2006; Mecikalski et al., 2007).

The general atmospheric conditions under which inservice icing may occur are fairly well known (Grzych and Mason, 2010): either large amounts of supercooled cloud droplets or high concentrations of ice particles are present. Events generally occur in clouds and anvils associated with various forms of predominantly tropical convection (mesoscale systems, multicellular clusters, tropical systems, and isolated cells). Events are typically associated with high cloud water content, weak to modest atmospheric instability, and modest wind shear.

However, the majority of in-service icing events appear to occur outside of what is called "classic" convection, i.e., areas of vigorous updrafts and overshoots. Approximately only $20 \%$ of reported in-service icing events are associated with this "classic" convection. Furthermore, areas of large concentrations of small ice particles are difficult to detect by onboard radar, in contrast to the "classical" convection where the deep convection and vigorous cores are detected by onboard radar and thus can be avoided. This may explain why only $20 \%$ of the reported events are associated with classic convection: such environments can generally be avoided by use of the onboard weather radar. Note that, although the majority of in-service icing events have been reported for tropical and subtropical regions of the world $\left(30^{\circ} \mathrm{N}-30^{\circ} \mathrm{S}\right)$, inservice conditions may also occur at higher latitudes. Given the current lack of a comprehensive picture of what actually happens physically with aircraft and engines during such events, it is not possible to specify the corresponding atmospheric conditions in more detail, and thus how to identify or diagnose such conditions.

To address many of the issues related to in-service icing events and in anticipation of regulation changes regarding mixed-phase and glaciated icing conditions, the large European High Altitude Ice Crystals project (HAIC) was initiated in 2012 to investigate a wide range of aspects of in-service icing. The HAIC project combines laboratory experiments (wind chambers), field campaigns in cooperation with the American High Ice Water Content (HIWC) project, numerical modeling, and remote sensing techniques to study a variety of aspects of in-service icing.
Amongst others, HAIC aims at characterizing the atmospheric conditions for possible in-service icing and the detection of such areas in satellite remote sensing products. Within this context, an important aspect of the HAIC project is the development of spaceborne remote detection and nowcasting application of glaciated icing conditions based on imagery of geostationary MSG SEVIRI (Meteosat Second Generation Spinning Enhanced Visible and InfraRed Imager) satellite observations, which did not exist prior to HAIC. As noted above, due to the lack of detail understanding of inservice events it is difficult to characterize in detail the atmospheric under which such events may occur - which is also the prime justification for the HAIC project. However, it is widely accepted that the presence of high ice water content - in this paper defined as IWC $>1 \mathrm{~g} \mathrm{~m}^{-3}$ - is a crucial condition for the occurrence of in-service icing and accepted as an alternative for detection of atmospheric in-service icing conditions. Detection of areas of potential high ice water content by satellite remote sensing thus provides important spatiotemporal information for the possible occurrence of in-service icing events. The HAIC project identified two possible approaches: use of pixel-based detection of cloud properties like the Cloud Physical Properties (CPP) algorithm (Roebeling et al., 2006; Meirink, 2013) and an objectbased approach using the Rapidly Developing Thunderstorm data product (RDT; Autonès, 2012), which identifies areas and contours of active convection based on characteristics of cloud systems.

In this paper, we present a high IWC mask aimed at identifying atmospheric environments with IWC exceeding $1 \mathrm{~g} \mathrm{~m}^{-3}$. The high IWC mask is based on the output of the CPP algorithm, which was developed within the Climate Monitoring Satellite Application Facility (CMSAF) of the EUropean METeorological SATellite organization (EUMETSAT) and applied to the geostationary SEVIRI satellite measurements. The CPP algorithm provides a number of cloud physical properties that are of interest in diagnosing possible in-service icing conditions. The high IWC mask will be derived and evaluated against measurements of cloud properties from active remote sensing instruments on board satellites, and finally the high IWC mask will be compared with the EUMETSAT SEVIRI RDT product to check whether the occurrence of high IWC environments is not only confined to active convection.

It is important to stress that the high IWC mask will not be optimized for its practical use and usefulness in aviation or the choice in the number of CPP parameters or CPP parameter threshold values. As we will show, the performance of the high IWC mask in terms of probability of detection (POD) and false alarms varies depending on the choices made, and both are intertwined with generally a better detection that results in more false alarms. Depending on needs and wishes be it from an aviation perspective or a scientific perspective different choices of parameter settings could be made. However, these needs and wishes are neither defined within the 
HAIC project nor part of the objectives of this paper. Hence, the focus in this paper is solely on determining whether detection of high IWC environments with a geostationary passive satellite sensor is possible with a - somewhat subjective - satisfactory performance.

\section{Project description and datasets used}

\subsection{HAIC}

Within the European FP7 HAIC project, academics and aeronautic industries are collaborating within six main research activities that include dedicated field campaigns, development of new in situ probes, space-based detection and monitoring, upgrade of onboard weather radars, improvement of ground test facilities, and modeling of melting and impingement processes. All activities are designed to enhance aircraft safety when flying in mixed-phase and glaciated icing conditions.

The HAIC sub-project 3 (SP3), entitled Space-borne Observation and Nowcasting of High Ice Water Content Regions, focuses on the development of spaceborne remote detection of high IWC and nowcasting techniques to support HAIC field campaigns and ultimately provide relevant near real-time weather information through air traffic management. The SP3 investigations are divided in three interacting work packages (WPs): (i) geostationary spaceborne retrievals of high IWC events focusing on the detection of high IWC cloud regions from the SEVIRI imager on MSG in daytime, as the CPP algorithm critically depends on information of observed solar radiation; (ii) polar orbiting spaceborne retrievals of high IWC events investigating the detection of high IWC cloud regions from visible (VIS), infrared (IR), and microwave passive and active observations of the spacebased A-train mission; (iii) nowcasting of tropical convection dedicated to the tracking of deep convection over the tropical Atlantic for operational applications based on the RDT nowcasting tool. Following the HAIC technology readiness level (TRL) strategy, the SP3 activities are required to pass with success three TRLs: TRL3 (characteristic proof of concept), TRL5 (breadboard validation in relevant environment), and TRL6 (prototype demonstration in a relevant environment).

\subsection{MSG-CPP}

The CPP algorithm (Roebeling et al., 2006; Meirink, 2013) uses SEVIRI's VIS and near-infrared (NIR) measurements to retrieve cloud optical thickness $(\tau)$ and cloud particle effective radius $\left(r_{\mathrm{e}}\right)$ by applying the classical Nakajima and King (1990) approach. This approach is based on the basic feature that the reflectance at a for cloud particles nonabsorbing wavelength is primarily related to $\tau$, while the reflectance at an absorbing wavelength is mainly related to $r_{\mathrm{e}}$. For SEVIRI retrievals the VIS $0.64 \mu \mathrm{m}$ and the NIR $1.63 \mu \mathrm{m}$ channels have been used here as non-absorbing and absorb- ing channels, respectively. At around $1.63 \mu \mathrm{m}$ ice particles are more absorbing than water droplets, which is not the case at $0.64 \mu \mathrm{m}$. Hence, together with the use of a thermal IR window channel to inform on cloud top temperature, this allows to retrieve cloud thermodynamic phase.

CPP is based on lookup tables (LUTs) of top-ofatmosphere reflectances for single-layer, plane-parallel water and ice clouds, simulated by the Doubling Adding KNMI (DAK) radiative transfer model (Stammes, 2001). Singlescattering properties have been calculated using Mie theory for spherical water droplets and ray tracing for imperfect hexagonal ice crystals (Hess et al., 1998). Absorption by atmospheric trace gases is taken into account based on Moderate Resolution Atmospheric Transmission code simulations (MODTRAN4 version 2; Anderson et al., 2001). For cloudy pixels (cloud contaminated or cloud filled, as determined by the cloud mask described in Roebeling et al., 2006) $\tau$ and $r_{\mathrm{e}}$ are retrieved by matching the observed reflectance to the LUTs. First the ice cloud LUT is tried. If this leads to a match and if the cloud top temperature - retrieved from the $10.8 \mu \mathrm{m}$ channel - is below $265 \mathrm{~K}$, the thermodynamic phase is set to ice. Otherwise, the water cloud LUT is used, and the phase is set to liquid. Liquid and ice water path (LWP and IWP) are then calculated following Stephens (1978):

LWP $=\frac{4}{3 Q_{\mathrm{e}}} \rho_{1} r_{\mathrm{e}} \tau ; \quad$ IWP $=\frac{4}{3 Q_{\mathrm{e}}} \rho_{\mathrm{i}} r_{\mathrm{e}} \tau$,

where $Q_{\mathrm{e}}$ is the extinction efficiency at visible wavelengths (set to 2), and $\rho_{1}$ and $\rho_{\mathrm{i}}$ are the densities of water and ice, respectively. Equation (1) assumes a vertically homogeneous distribution of cloud condensate. CPP uses surface albedo at the VIS and NIR channels based on MOderate Resolution Imaging Spectroradiometer (MODIS; Moody et al., 2005) and water vapor path from the ERA-Interim reanalysis project (Dee et al., 2011) of the European Center for Medium range Weather Forecast (ECMWF) as ancillary input data. Cloud property retrievals become very uncertain at high solar zenith angles (SZAs) $\left(\theta_{0}\right)$ and viewing zenith angles $(\theta)$. Therefore, no retrievals are performed for $\theta_{0}>78^{\circ}$ or $\theta>78^{\circ}$. Earlier versions of CPP have been extensively validated using ground-based observations (Roebeling et al., 2008; Wolters et al., 2008) and used for the evaluation of regional climate models (Roebeling and van Meijgaard, 2009; Greuell et al., 2011). Detailed information on the CPP version used can be found in Meirink (2013).

Note that the CPP parameters associated with reflected solar radiation are mostly representative for the upper parts of clouds, in particular in case of optically thick clouds (e.g., deep convection). Because of the reliance of CPP on reflected solar radiation most of the photons are reflected back from the upper parts of optically thick clouds (Platnick, 2000). Hence, little information from deep within optically thick clouds can be obtained.

Also note that unpublished results indicate that CPP $r_{\mathrm{e}}$ does not correlate very well with local cloud conditions. Fur- 
thermore, the physical interpretation of $R_{\text {eff }}$ is rather complicated and care should be taken with interpreting $R_{\text {eff }}$ as representative for real-world cloud particles sizes, in particular for ice clouds (e.g., McFarquhar and Heymsfield, 1998; Mitchell et al., 2011).

\subsection{DARDAR (raDAR-liDAR)}

DARDAR (Delanoë and Hogan, 2008, 2010) consists in two synergistic products derived from the combination of the CloudSat radar (Stephens et al., 2002) and CALIPSO (Cloud-Aerosol Lidar and Infrared Pathfinder Satellite Observations) lidar (Winker et al., 2009) measurements. These products are distributed through the ICARE center in Lille (France). The first one, DARDAR-MASK (Delanoë and Hogan, 2010; Ceccaldi et al., 2013), is mainly a target classification of the scene observed by both CloudSat and CALIPSO. More precisely the DARDAR-MASK dataset employs a combination of the CloudSat and CALIPSO measurements to identify cloud, precipitation, and aerosol presences and also retrieve cloud-phase properties. The algorithm, based on a decision tree, was originally designed to identify ice clouds on the basis of the synergy of surfacebased radar, lidar observations. The DARDAR-MASK returns a range of categories: clear, ground, stratospheric features, insects, aerosols, rain, supercooled liquid water, liquid warm, mixed phase, and ice. The algorithm also permits an "unknown" classification when it is not possible to determine one of these categories (Delanoë and Hogan, 2010). This commonly occurs in regions where the radar and lidar signal have been heavily attenuated or are missing. DARDARMASK used CALIPSO backscatter and temperature to identify supercooled water in the 0 to $-40{ }^{\circ} \mathrm{C}$ range (Ceccaldi et al., 2013), while the depolarization is considered too noisy to be used at the CALIPSO resolution (Delanoë and Hogan, 2010).

Ice cloud properties are available in the second DARDARCLOUD product (Delanoë and Hogan, 2010). This product uses the "varcloud variational technique" (Delanoë and Hogan, 2008), which combines the CloudSat radar and CALIPSO lidar profiles for retrieving the extinction coefficient, IWC, and $r_{\mathrm{e}}$ of the ice cloud. DARDAR-CLOUD assumes a "unified" particle size distribution given by Delanoë et al. $(2005,2014)$. The mass-size and area-size relations of non-spherical particles are considered using in situ measurements (Brown and Francis, 1995; Francis et al., 1998; Delanoë et al., 2014). Errors of DARDAR IWC are estimated at $<20 \%$; (Delanoe et al., 2014). Only for very high DARDAR IWC $\left(>2 \mathrm{~g} \mathrm{~m}^{-3}\right)$ have substantial biases been found that require care be taken in its application. For the use of DARDAR IWC in this study (IWC threshold at $1 \mathrm{~g} \mathrm{~m}^{-3}$ ) this bias is not relevant.

\subsection{Rapidly Developing Thunderstorm (v2013)}

Because in-service icing events are frequently associated with convective systems, it is valuable to evaluate the CPP performance against satellite data products specifically designed to identify active convection, and RDT is such a data product. A comparison with RDT will thus show whether or not the high IWC mask correlates well with the occurrence of active convection and whether high IWC can also be expected to occur outside of active convective regions. Also note that RDT is an object-identifying algorithm (shapes, contours), based on general cloud characteristic of the object, which is fundamentally different from the pixel-based approach of CPP.

RDT tracks clouds, identifies those that are convective, and provides a description of their microphysical, morphological, and dynamical properties. In particular, it allows locating the boundaries of the cells and the overshooting tops when present. This last characteristic is of a great importance for aircraft safety as overshooting is associated with strong updrafts. The RDT also estimates the cell vertical extent, its horizontal growth rate, and cooling rate necessary for estimating the intensification/decaying of the convective cell. The speed and direction of propagation are also provided. Two other important parameters are available in RDT product for icing issues: the main cloud phase of the convective cell and the highest convective rain rate inside the cell, both coming from other NWCSAF (Satellite Application Facility in Support to Nowcasting and Very Short Range Forecasting) algorithms and integrated into the RDT output. The RDT algorithm is based on four main modules: the detection, the tracking, the discrimination, and the advection scheme. The RDT software is developed by Météo France in the framework of NWCSAF.

RDT combines a cloud-tracker and an algorithm to discriminate convective and non-convective cloud objects. The cloud objects defined by the RDT are cloud towers with a significant vertical extension, namely at least $6^{\circ} \mathrm{C}$ colder than the warmest pixel in the surrounding (Guillou et al., 2009). For that purpose, the $10.8 \mu \mathrm{m}$ channel of MSG is used. The tracking algorithm allows linking an object on the previous image. Once the link is identified, some characteristics of the object can be calculated, such as trends (e.g., cooling rate) and motion vector (considering successive positions of the gravity center). Then the third step is a statistical scheme to define whether the cell is convective or not. The statistical scheme, called discrimination, depends on the available satellite data as well as historic data. In optimal configuration it requires for the following satellite channels: water vapor channels at 6.2 and $7.3 \mu \mathrm{m}$ and thermal infrared channels at 8.7, 10.8, and $12.0 \mu \mathrm{m}$. Empirical rules help to classify convective systems. The coordinates of each cell are available as a polygon including associated characteristics. For the comparison with the MSG-CPP high IWC mask we focus on the 
agreement between the location of RDT objects and the high IWC mask.

\subsection{AIRBUS in-service event database}

Within the HAIC project, AIRBUS has provided a global database of "in-service" events of icing, i.e., reports by pilots of flying conditions where icing apparently has affected flying conditions. Due to AIRBUS regulations the database is not public, but information can be obtained via AIRBUS in case of use for scientific research.

\section{High IWC mask}

\subsection{Analysis of AIRBUS event database and development of a provisional high IWC mask}

Within the HAIC project, the AIRBUS "in-service" event database was used to construct a first provisional high IWC mask (v1). Details of its construction can be found in the Supplement (S1.1 and 1.2). The mask is based on defining thresholds for a set of CPP parameters: only if all criteria are met, i.e., the CPP parameter values fall within the predefined threshold intervals, is the SEVIRI pixel masked as a high IWC event. The MSG-CPP parameter threshold values used for defining the high IWC mask v1 are listed Table S1 in the Supplement.

The number of useful events in the database is limited (only nine daytime events within the SEVIRI disc), casting doubt about the usefulness of the database and thereby the provisional high IWC mask v1. Hence, an alternative approach was agreed upon by the HAIC project leaders, whereby identification of high IWC values $\left(>1 \mathrm{~g} \mathrm{~m}^{-3}\right)$ in satellite vertical profile measurement of water content serves as a proxy for in-service icing conditions (Fridlind et al., 2015; Ackerman et al., 2015). Nevertheless, a qualitative analysis of the AIRBUS database events showed that events can be associated with mesoscale convective systems, squall lines, small-scale single cell convection, as well as persistent dense cirrus that is not immediately and easily associated with a particular convective event.

\subsection{Optimization of the MSG-CPP high IWC mask}

The CPP high IWC mask v1 was evaluated against a small set of in-service events, providing limited information on the mask performance. To optimize the CPP high IWC mask, additional verification and evaluation tests are needed. The DARDAR profile measurements provide the required highvertical-resolution cloud information for this optimization. A DARDAR test dataset was constructed, consisting of 31 daytime orbits in the year 2008, covering all months, randomly distributed throughout the SEVIRI disc, and containing a sufficient number of high IWC measurements within one orbit (see Supplement Table S2). Note that before op- timization of the mask, a detailed characterization of MSGCPP cloud properties was performed using these 31 DARDAR orbits (see S1.3 in the Supplement).

The performance of the MSG-CPP high IWC mask v1 then was evaluated against these DARDAR orbits. In Fig. 1, DARDAR orbit profiles were ranked according to the maximum IWC value in the profile, after which the percentage of DARDAR profiles identified by the high IWC mask v1 was calculated. Clearly, the number of high IWC events identified by the high IWC mask is very limited. The insert shows the same data but for the different thresholds that are used for the high IWC mask v1. The most important limiting factor here is the condensed water path (CWP), with the cloud top height (CTH) and/or cloud top temperature (CTT) being of secondary importance. The latter is not surprising, as the maximum IWC value not necessarily is located higher up in the troposphere (either $>8 \mathrm{~km}$ or below $225 \mathrm{~K}$ ). This analysis shows that the mask performance is particularly sensitive to the CWP, CTT, and cloud optical thickness (COT). Hence, for optimizing the MSG-CPP high IWC mask a sensitivity analysis should be performed using DARDAR profile measurements and varying MSG-CPP parameter values to see whether a more optimal set of MSG-CPP parameter thresholds can be defined for identification of high IWC events. The performance of the high IWC mask was tested for the following range of MSG-CPP parameter threshold values:

$$
\begin{aligned}
& \text { - CWP is > 100-1000 } \mathrm{g} \mathrm{m}^{-2} \text { with } 100 \mathrm{~g} \mathrm{~m}^{-2} \text { steps; } \\
& \text { - CTT <275-225 K with } 5 \mathrm{~K} \text { steps; } \\
& \text { - COT 5-20 with steps of five units. }
\end{aligned}
$$

The effective radius was left out as it is generally not representative for the $r_{\mathrm{e}}$ at the level of the highest IWC occurrence (see earlier discussion). The cloud top height was left out as it is closely related to the cloud top temperature.

The subsequent statistic of identification of high IWC events by the high IWC mask as function of maximum IWC value in the DARDAR profile was then analyzed according to the following characteristics: the steepness of the increase in fraction of DARDAR profiles identified by the high IWC mask in the IWC $_{M A X}$ interval between 0.1 and $1 \mathrm{~g} \mathrm{~m}^{-3}$ and the fraction of maximum DARDAR IWC $>1 \mathrm{~g} \mathrm{~m}^{-3}$ identified by the high IWC mask.

The best high IWC mask consists of those combinations of MSG-CPP parameters that identify DARDAR IWC $>1 \mathrm{~g} \mathrm{~m}^{-3}$ while rejecting DARDAR IWC $<1 \mathrm{~g} \mathrm{~m}^{-3}$. This is in essence a binary decision model - also known as a contingency model - as outlined in Table 1, which shows a prototypical contingency table for decision-making. Given that the large majority of MSG-CPP pixels will not be identified as high IWC events (see Fig. 1), we focus on the following three verification statistics: the hit rate or POD, the false alarm ratio (FAR), and the threat score or critical success index (CSI), the latter of which is often being used for 
Table 1. Decision table for MSG-CPP high IWC mask.

\begin{tabular}{lcccc}
\hline & \multicolumn{3}{c}{ DARDAR } \\
\cline { 2 - 5 } MSG-CPP & \multicolumn{3}{c}{ IWC $_{\text {MAX }}>1 \mathrm{~g} \mathrm{~m}^{-3}$} & IWC $_{\text {MAX }}<1 \mathrm{~g} \mathrm{~m}^{-3}$ \\
\hline High IWC mask $=$ true & {$[\mathrm{A}]$} & True (true positive) & {$[\mathrm{B}]$} & False (false positive) \\
High IWC mask $=$ false & {$[\mathrm{C}]$} & False (false negative) & {$[\mathrm{D}]$} & True (true negative) \\
\hline
\end{tabular}

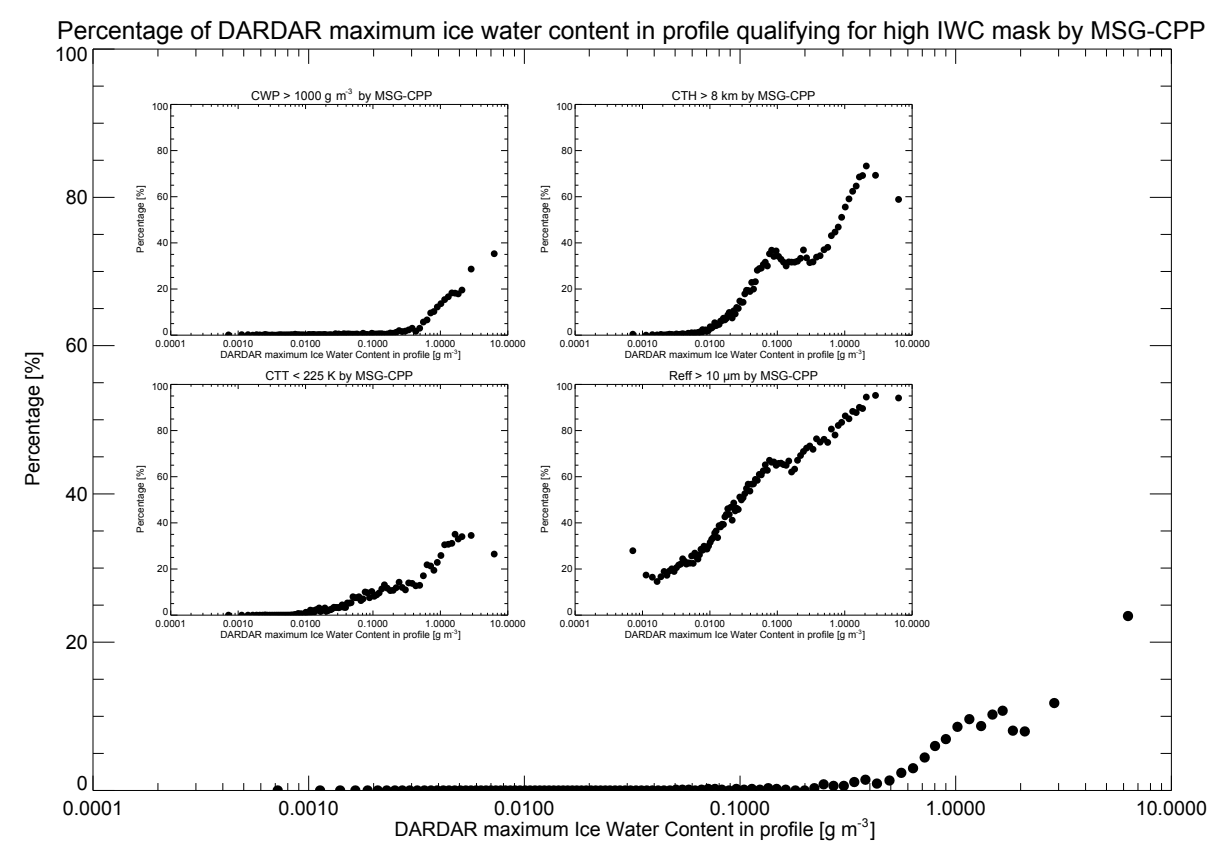

Figure 1. Fraction of DARDAR profiles identified by MSG-CPP high IWC mask v1. DARDAR profiles are sampled according to the maximum IWC value within the profile. The insert shows the same statistic but for different MSG-CPP parameter thresholds used in the MSG-CPP high IWC mask v1 separately.

low-frequency events. These statistics can be used to objectively select the best combination of MSG-CPP parameters thresholds. Based on Table 1, these three statistics are calculated as follows (see Eq. 1):

$\mathrm{POD}=\frac{A}{A+C} \quad \mathrm{FAR}=\frac{B}{A+B} \quad \mathrm{CSI}=\frac{A}{A+B+C}$.

Figure 2 shows the probability distribution of the POD (upper panel), FAR (middle panel), and CSI (lower panel) for different MSG-CPP parameter threshold settings (see legend of Fig. 2 for more details). The probability distribution of PODs varies between 0 and 0.9 , with a gradual decrease in occurrence of increasing POD. The probability distribution of the FAR starts only at 0.3 and has a distinct peak around 0.4 with a long tail up to values of 0.95 , showing that to some extent "false alarms" in MSG-CPP cannot be avoided. The CSI shows a broad distribution between 0 and 0.4 .

If we look at the relation between the POD and FAR as well as between the POD and CSI - shown in Fig. 3 - we see that increasing POD also results in increasing FAR; thus better detection of high IWC values in DARDAR IWC pro- files by MSG-CPP is accompanied by an increasing number of "false alarms". The relation between the POD and the CSI shows this effect with a maximum around a POD value of 0.6 and a decreasing but also widening distribution of the CSI with increasing POD beyond 0.6, reflective of the problem of more false positives with a better POD.

For defining the high IWC we investigated the CPP parameter thresholds and focused on CSIs close to the maximum CSI encountered in Fig. 3 (CSI $>0.35$ ). There is some freedom of choosing the CPP parameter threshold values as different combinations yield similar CSI values. A brief analysis (not shown) of the parameter combinations that led to the highest CSI values suggests that a conservative selection requires a minimum CWP threshold value of $100 \mathrm{~g} \mathrm{~m}^{-2}$, a CTT $<270 \mathrm{~K}$, and a COT $>20$. For version 2 of the high IWC mask, the CPP parameter threshold values are as follows. 

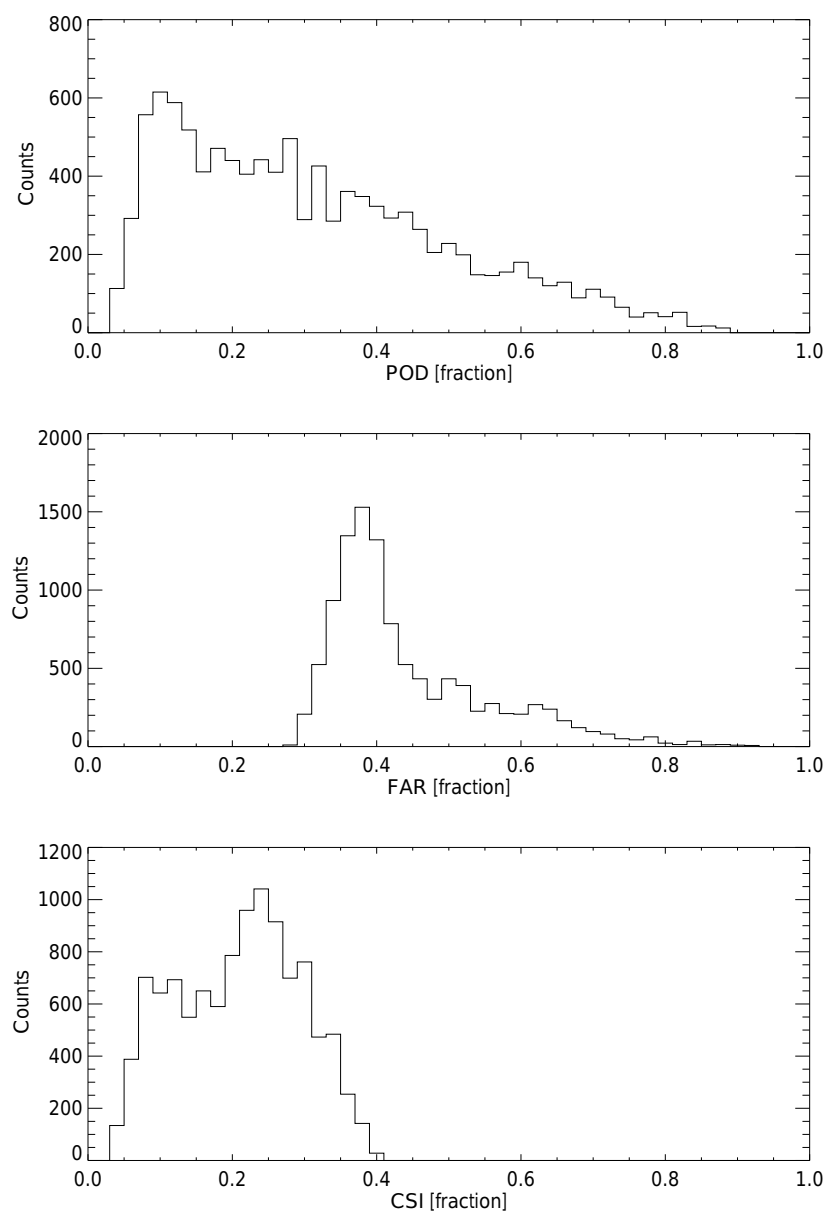

Figure 2. The MSG-CPP parameter threshold settings were varied as follows: $100<\mathrm{CWP}<1000$ with steps of $100 \mathrm{~g} \mathrm{~m}^{-2}$; $225<\mathrm{CTT}<275$ with steps of $5 \mathrm{~K} ; 0<\mathrm{COT}<100$ with steps of 10 (no unit); and the height of the maximum IWC values in the DARDAR profile varying between 1 and 9 with steps of $1 \mathrm{~km}$.

- The cloud phase: ice

- The effective radius: no threshold

- Condensed water path: $>100 \mathrm{~g} \mathrm{~m}^{-2}$

- Cloud top height: no threshold

- Cloud top temperature: $<270 \mathrm{~K}$

- Cloud optical thickness: $>20$

This combination of thresholds has a POD of 0.59 , a FAR of 0.52, and a CSI of 0.36. For the same DARDAR data but with the high IWC mask v1, POD is 0.08 , FAR is 0.34 , and CSI is 0.08 . Both the POD and CSI are better for v2 compared to high IWC mask v1. The FAR is better for v1 compared to high IWC mask v2, indicative of the trade-off between detection and false alarms as discussed in relation to Fig. 3. The better POD and CSI are also reflected in the notion that the number of detections of DARDAR IWC profiles with maximum IWC $>1 \mathrm{~g} \mathrm{~m}^{-3}$ is in high IWC mask v2 an order of magnitude larger than in high IWC mask v1 (see Fig. 4).
We realize that there is no unique or best set of threshold values, as there are two competing interests: better detection of high IWC events vs. fewer false alarms. Furthermore, it is a priori not clear what the defining characteristics of an high IWC mask should be, as the number of real in-service icing events is rather limited. As it is unclear what the exact atmospheric conditions for the occurrence of in-service icing are to begin with, there are no compelling arguments to specifically choose for other threshold values as long as the favored statistic (CSI) is close to the maximum CSI found in the sensitivity analysis.

We also ran a test accounting for the time difference between the DARDAR measurement and the MSG-CPP measurement (once every $15 \mathrm{~min}$ ). For the verification discussed here the DARDAR measurements were coupled to the nearest MSG-CPP measurement in space and time (which thus can be either before or after the DARDAR measurement). A test with either the nearest MSG-CPP measurement before the DARDAR measurement or the nearest MSG-CPP measurement after the DARDAR measurement did result in very similar verification statistics (change in all verification statistics less than \pm 0.05 ).

Finally, we checked the verification statistics for the subMSG-CPP pixel average DARDAR profile and the parallax correction. The MSG-CPP pixel size - typically $5 \mathrm{~km}-$ is much larger than the footprint of DARDAR profile - typically $250 \mathrm{~m}$. As a check, we ran the same verification for the MSG-CPP pixel average DARDAR profile. Obviously this results in fewer collocations. However, for only $10 \%, 2 \%$, and $0.1 \%$ of the DARDAR profiles with maximum IWC above $1 \mathrm{~g} \mathrm{~m}^{-3}$, was the maximum IWC in the corresponding average IWC profile less than $1 \mathrm{~g} \mathrm{~m}^{-3}, 0.5 \mathrm{~g} \mathrm{~m}^{-3}$, and $0.1 \mathrm{~g} \mathrm{~m}^{-3}$, respectively. As a result, the verification statistics were very similar with changes of \pm 0.05 at maximum but generally less. Similar small changes in verification statistics were found when applying the parallax correction.

Figure 4 shows the results of the evaluation for the MSGCPP high IWC mask with DARDAR IWC profile measurements. The higher the maximum IWC value, the larger the chances of detection by the high IWC mask. The results also show that the high IWC mask identifies the majority $(50-60 \%)$ of the DARDAR profiles that we aim to detect (IWC $>1 \mathrm{~g} \mathrm{~m}^{-3}$ ), compared to an identification rate of less than $10 \%$ with high IWC mask v1. In addition, the higher the altitude of maximum IWC in DARDAR, the higher the percentage of these cases identified by the high IWC mask v2, increasing to almost $80 \%$ for DARDAR maximum IWC altitudes $>8 \mathrm{~km}$ compared to $50-60 \%$ for all cases combined. This is consistent with earlier findings indicating that SEVIRI/MSG-CPP is more sensitive to the physical conditions of the upper part of a cloud. However, for the DARDAR cases with maximum IWC $<1 \mathrm{~g} \mathrm{~m}^{-3}$ yet still identified by the high IWC mask v2 (false detections), the maximum IWC is for the majority of cases still $>0.1 \mathrm{~g} \mathrm{~m}^{-3}$ (approximately the 20th percentile of the IWC distribution; 5th percentile for al- 

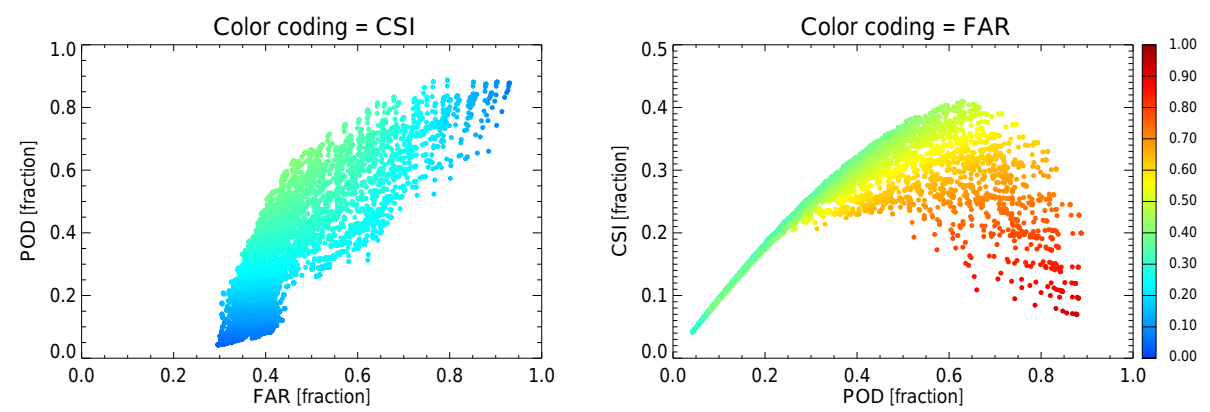

Figure 3. Probability of detection (POD) as a function of the false acceptance rate (FAR) and critical success index (CSI) as a function of the POD for different definitions of the MSG-CPP high IWC mask definitions and their success in detecting high IWC values in DARDAR IWC profile data.

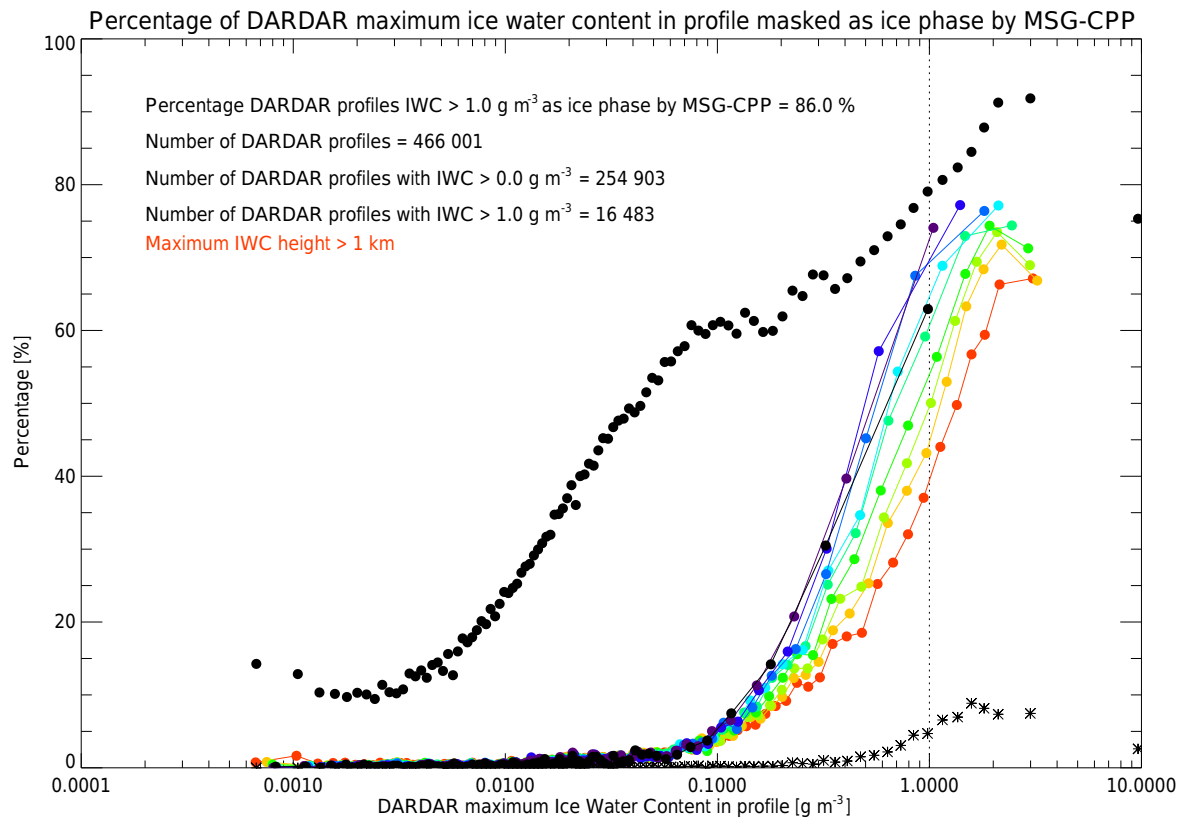

Figure 4. Similar to Fig. 1 (asterisks, high IWC mask v1) but for high IWC mask v2. The black dots indicate the number of MSG-CPP cloud identified as ice given the maximum IWC within the DARDAR profile. The colored lines indicate the percentage of MSG-CPP pixels that qualify for the high IWC mask v2 pixels for DARDAR profiles with the height of the maximum IWC above the given altitude. See the main document for a description of the corresponding MSG-CPP parameter thresholds.

titudes $>8 \mathrm{~km}$ ). In other words, for most false detections by the high IWC mask v2 the maximum IWC is still quite high, just not above the threshold value. Most of the false detections are thus not false in the sense that there is no IWC. If IWC values larger than $0.1 \mathrm{~g} \mathrm{~m}^{-3}$ are accepted, the FAR drops from 0.51 to 0.14 . Finally, and just for reference, in general many more MSG-CPP clouds are identified as ice by the MSG-CPP ice phase than by the high IWC mask, showcasing the effect the different MSG-CPP parameters used in the high IWC mask have.

Compared to the high IWC mask v1 the number of DARDAR profiles identified as high IWC events improves with the high IWC mask v2, with most high DARDAR profiles with IWC $>1 \mathrm{~g} \mathrm{~m}^{-3}$ now identified as high IWC events. Figure 4 further suggests the higher in altitude the high IWC value, the more likely it becomes that profiles with high but not extremely high maximum IWC values are identified by the high IWC mask. This is an important result, as it suggests that optically or vertically thick clouds with high IWC values lower in the troposphere are more difficult to identify by the high IWC mask.

The sensitivity of MSG-CPP parameter thresholds as presented in Figs. 2 and 3 shows that, although the high IWC mask certainly can be improved, there remains some room for choosing parameters. The typical uncertainty ranges we identified are 


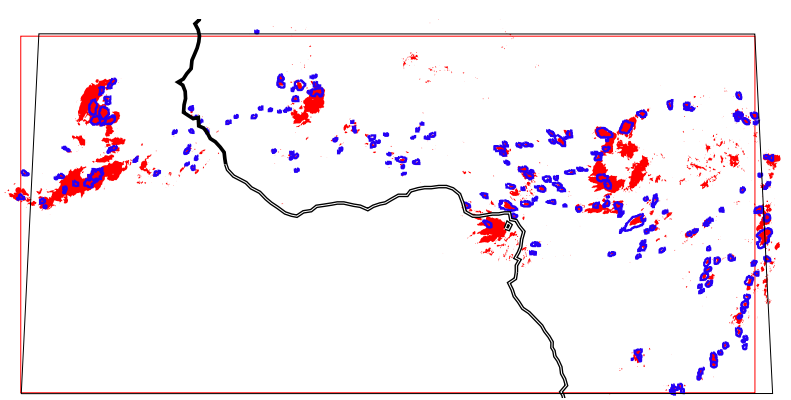

Figure 5. An example of the comparison between RDT areas (blue outlines) and the high IWC mask (red). RDT and the high IWC mask were taken on 7 September 2009 13:15:00 UTC. The black and red boxes are for visualization purposes only.

- cloud water path threshold between 100 and $400 \mathrm{~g} \mathrm{~m}^{-2}$;

- cloud top temperature threshold between 240 and $270 \mathrm{~K}$;

- cloud optical thickness threshold between 5 and 20.

These ranges should be kept in mind when using the high IWC mask; there is no optimal choice in MSG-CPP parameter threshold values.

\subsection{Comparison between the MSG-CPP high IWC mask and RDT}

An additional analysis was performed for comparing the high IWC mask and the MF RDT objects in order to evaluate whether both masks identify similar areas as potential high IWC environments and whether one mask is preferred or the two masks are complementary.

Météo France made RDT data available for three AIRBUS events and provided 1 complete day of RDT data surrounding each event. Figure 5 shows an example of the comparison between RDT and the high IWC mask. From visual inspection only it appears that for the larger RDT cells there is a considerable overlap between RDT and the high IWC mask. However, the large areas of high IWC mask appear considerably larger than the corresponding RDT area. In contrast, small RDT cells are generally not identified by the high IWC mask. Figure 6 shows the relation between the RDT size and the fraction of pixels identified by the high IWC mask. Clearly, the larger the cell, the larger the fraction of pixels identified. Note that this relation was also found for the other events.

Combining these results the following hypothesis emerges. Small RDT cells are young, fast-growing cells that are not completely iced yet. Only when convection reaches a sufficient mature stage do the clouds become fully iced. Once cells mature and become larger, their dynamic development slows and the corresponding anvils and/or high-altitude ice clouds become larger. Ultimately, convective activity ceases and the high-altitude cirrus remains, which is more likely to be identified by the high IWC mask than by RDT. This observation appears intuitively consistent with the common conceptual meteorological model of the evolution of convection.

In summary, RDT and the high IWC mask are complementary: RDT is very well capable of identifying young, smallgrowing convective cells, whereas the high IWC mask appears better capable of identifying mature and aging convection and/or cirrus.

\subsection{Solar zenith angle bias}

The MSG-CPP high IWC mask v2 has been implemented in an operational stream and made available in near real time on the KNMI MSG-CPP web portal (http://msgcpp.knmi.nl). One of the first impressions of the results of the implementation was that a SZA dependence of the high IWC mask v2 exists. It appeared that for high angles the high IWC mask had a tendency to occur at edges of clouds facing the sun, typically associated with frontal zones or convection. This tendency appeared to visually correlate with high cloud optical thicknesses and to cause a displacement of the COT compared to, for example, cloud top temperature. One possible hypothesis explaining this observation is that for optically thick and/or heterogeneous cloud systems and high solar zenith angles 3$\mathrm{D}$ radiative effects (e.g., illumination/shadowing of different parts of the cloud top) become very important and, due to the nonlinear relation between optical thickness and reflectance, cause larger increase of COT in the more illuminated parts than decrease in the less illuminated parts. An overall positive bias of retrieved COT at high SZA has been observed before in, for example, MODIS observations (Grosvenor and Wood, 2014).

To demonstrate that such a bias indeed exists we tracked and analyzed the tropical cyclone Humberto in the North Atlantic Ocean on 12 September 2013. Humberto was a category 1 hurricane system on the Saffir-Simpson Hurricane Wind Scale that formed in the Cape Verde region west of Africa on 8 September 2013. The system remained over the western Atlantic for approximately 12 days without causing much damage other than heavy rain on the Cape Verde Islands. On 11-12 September 2013 wind speeds reached hurricane strength (source: NOAA, http://www.nhc.noaa.gov/ data/tcr/AL092013_Humberto.pdf).

Because hurricanes are well defined and consist of fully developed cloud systems whose morphology and physical properties generally do not change very quickly during a period of $12 \mathrm{~h}$, they can be used to investigate SZA biases in the MSG-CPP output. Typically clouds of fully developed hurricanes reach up to the tropopause - resulting in fairly small changes in cloud top temperatures - and because of its energetics it is not expected that the amount of humidity, cloud water, and precipitation will change very quickly as hurricanes need a minimum sea surface temperature of $27^{\circ} \mathrm{C}$ to exist while the maximum sea surface temperature 

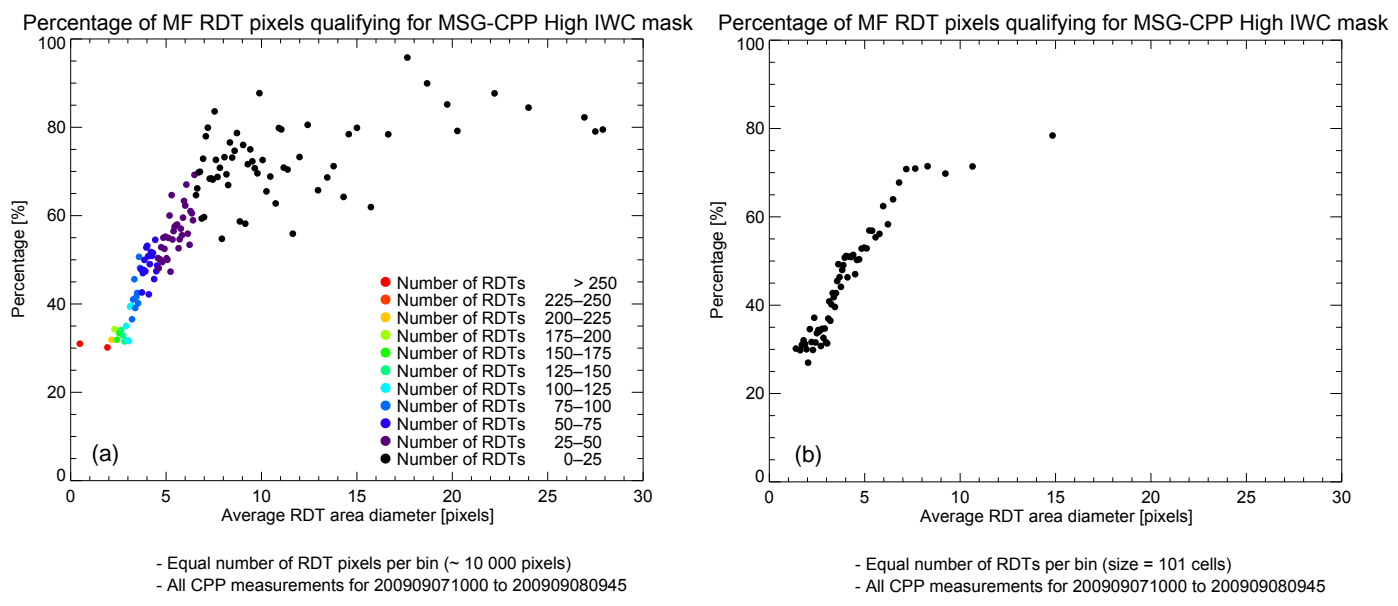

Figure 6. Correlation between average RDT area (square root of number of pixels with RDT cell) and fraction of pixels per cell identified by the high IWC mask for AIRBUS event 24. For the left plot each dot represents approximately of 10000 RDT pixels; for the right plot each dot represents an equal number of RDT cells (total number of RDT cells for day of event 24 is 12416 ). The color coding in the left plot indicates the number of RDT cells for each dot. The figure represents one $24 \mathrm{~h}$ period of RDT and MSG-CPP measurements on 7 and 8 September 2009.

rarely exceeds $33^{\circ} \mathrm{C}$. It is therefore not expected that physical properties change dramatically during a $12 \mathrm{~h}$ period for which MSG-CPP data are available.

Figure 7 shows the time evolution of a number of MSGCPP statistics and parameters for a $400 \times 400$ SEVIRI pixel area centered around $24.86^{\circ} \mathrm{N},-27.33^{\circ} \mathrm{E}$, which covers approximately a $20^{\circ} \times 20^{\circ}$ area. During this time the core of tropical hurricane Humberto was located within this area. Panel (a) shows that the number of CTT below $213 \mathrm{~K}$ $\left(-60^{\circ} \mathrm{C}\right)$ was fairly constant over the $12 \mathrm{~h}$ time period and slowly decreased, consistent with the reported weakening of the system on 12 September 2013. However, panel (b) shows that the occurrence of COT $>100$ is strongly peaked at the beginning (09:00-11:00 UTC) and the end (18:0019:00 UTC) of the period, when the counts double or triple compared to the fairly constant number of occurrences of COT $>100$ between 11:00 and 18:00 UTC. The corresponding area average SZA (panel c) and in particular the area average light path $(1 / \operatorname{cosine}(\mathrm{SZA})$ in panel d) shows a similar curvature. Finally, the number of high IWC masked pixels (panel e) is also fairly constant over the time period.

When comparing the correlation coefficients with the average light path $(1 / \operatorname{cosine}(\mathrm{SZA}))$, it is clear that the average SZA and in particular the average light path length correlates very well with the occurrence of COT $>100$. A typical SZA value for which this starts to become important is $60^{\circ}$. Note that for large SZA the light path could be an order of magnitude larger than for small SZAs. For the hurricane system studied here this does not bias the high IWC mask counts, presumably because the characteristics of clouds associated with a hurricane - cold, optically thick clouds with lots of condensed water - are such that they always qualify for the high IWC mask. Nevertheless, it is obvious that for other types of cloud systems the high IWC mask is likely less reliable for high SZA and/or high viewing angles, and this is consistent with the visual inspection of the data. Even for the well-organized cloud system of hurricane Humberto we could visually identify small misalignments between structures related to CTT and COT for large SZA that we could not identify for small SZA. However, it was difficult to quantify such slight misalignments; hence we reverted to the more general extremely high COTs measured in the hurricane for large SZAs. If we exclude CPP measurements for SZAs $>60^{\circ}$, the verification statistics of the DARDAR comparison improve slightly with the POD increasing from 0.59 to 0.62 , the FAR decreasing from 0.52 to 0.49 , and the CSI increasing from 0.36 to 0.39 .

\section{Summary and conclusions}

For the detection of potential (high-latitude) high ice water content in SEVIRI geostationary satellite measurements a mask was constructed based on the results from the CPP algorithm. The mask is based on defining thresholds for a set of CPP parameters: only if all criteria are met, i.e., the CPP parameter values fall within the pre-defined threshold intervals, is the SEVIRI pixel masked as a high IWC event.

Evaluation of the high IWC mask with satellite measurements of active remote sensors of cloud properties (CLOUDSAT-CALIPSO combined in the DARDAR product) shows that the high IWC mask is capable of detecting high IWC values $>1 \mathrm{~g} \mathrm{~m}^{-3}$ in the DARDAR profiles with a probability of detection of $60-80 \%$. A detailed sensitivity analysis of SEVIRI thresholds and subsequent statistical analysis shows that a better detection of high IWC events is accompanied by more false negatives. We decided on a 

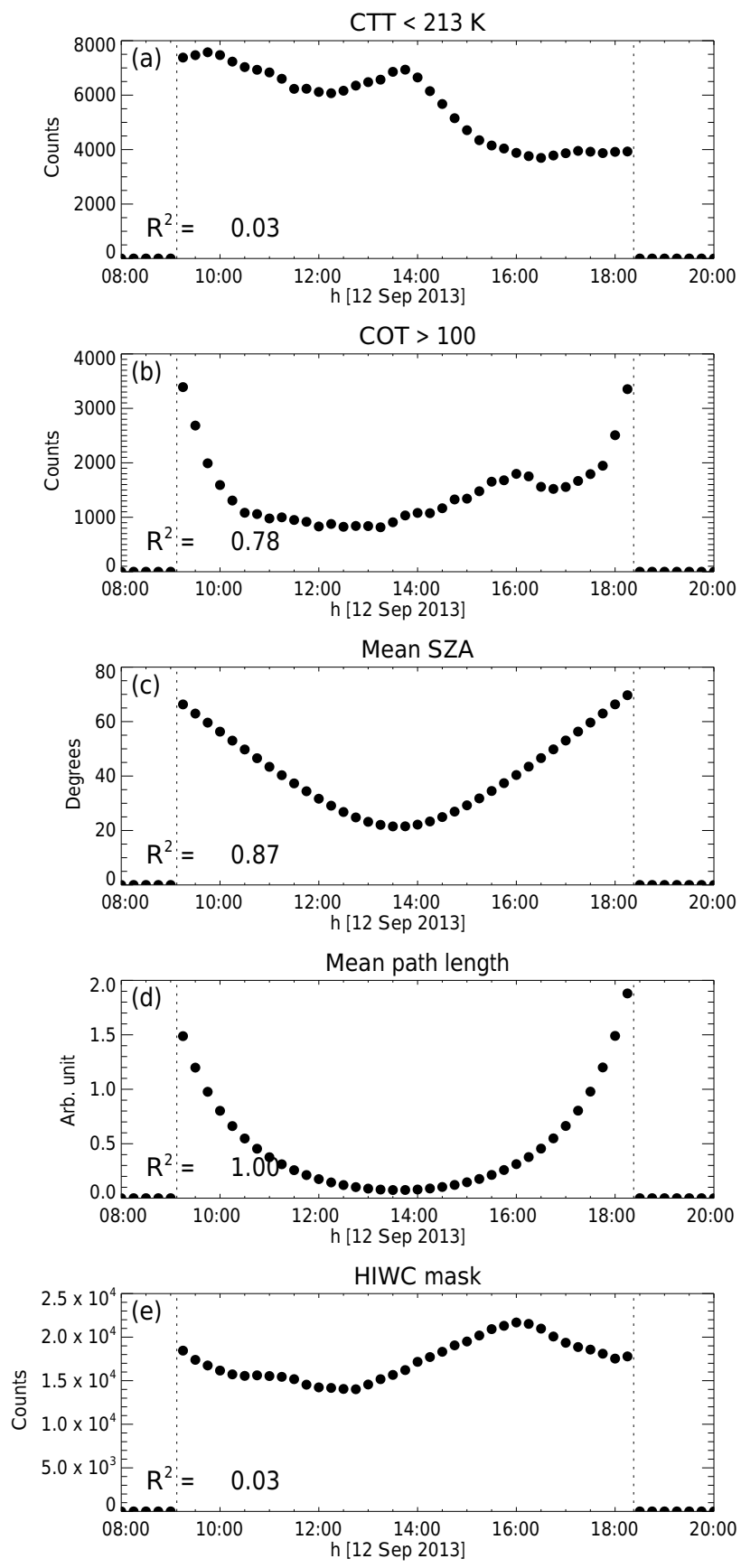

Figure 7. SEVIRI and MSG-CPP statistics of tropical hurricane Humberto on 12 September 2013. Panel (a) shows the number of SEVIRI pixels with cloud top temperatures $<213 \mathrm{~K}\left(-60^{\circ} \mathrm{C}\right)$, (b) shows the number of SEVIRI pixels with COT $>100$, (c) shows the average SZA for the area, (d) shows the mean path length $(1 / \cos (\mathrm{SZA}))$ of the area, and (e) shows the number of SEVIRI pixels qualifying for the MSG-CPP high IWC mask. Between the dotted lines are the times when data were available for all SEVIRI pixels within the area MSG-CPP. The correlation coefficients denote the time correlation of the parameter shown within the panel and the mean path length in (d) and only for the period between the dotted lines. combination of thresholds that maximize the CSI, but users should be aware that depending on requirements user preferences the parameters thresholds could be changed. Furthermore, the evaluation of results against DARDAR provided some indications that the MSG-CPP high IWC mask is more sensitive to cloud ice or cloud water in the upper part of the cloud, which is relevant for aviation purposes. This will be a focus of future research.

Comparison with results from the RDT algorithm applied to the same geostationary SEVIRI data showed that there are similarities and differences with the high IWC mask: the RDT algorithm is very capable of detection of young/new convective cells and areas, whereas the high IWC mask appears to be better capable of detecting more mature and ageing convection as well as cirrus remnants. This is likely related to the fact the RDT is developed for detecting fastgrowing thunderstorms which may not have that much high IWC yet. Once dynamical development of thunderstorms and convective systems ceases, RDT is unable to identify those regions but the high IWC mask still can as there is sufficient ice remaining.

Visual inspection of high IWC mask fields suggested that there could be SZA-dependent biases in some of the MSGCPP products. An analysis of a hurricane system in the tropical Atlantic (Humberto, September 2013) revealed that the MSG-CPP COT can be biased for high SZAs as the light path through high-altitude (ice) clouds can become very large and will not be fully representative of the real vertical cloud structure anymore. Under such circumstances, the high IWC mask can be biased, although for the Humberto hurricane we did not find evidence of increased high IWC mask occurrences, probably because hurricane systems will always be characterized by generally high IWC throughout the system. Nevertheless, some care has to be taken with the high IWC mask under conditions of extreme SZAs and extreme viewing angles, and a first estimate indicates that excluding MSG-CPP measurements with SZAs $>60^{\circ}$ slightly improves the verification statistics of the comparison of the high IWC mask with the DARDAR measurements. Note that it is equally likely that similar errors may occur due to the viewing geometry, something that we believe we could also identify visually but which was difficult to characterize quantitatively.

Although the high IWC mask is successful at detecting high IWC values in IWC profiles measured by active remote sensing sensors, it should be noted that it remains unclear what the exact conditions are of in-service icing. It is well established that high IWC values are likely a condition for the occurrence of in-service icing, but clearly it is not the only condition for these occurrences. The lack of detailed understanding of what causes such events precludes further fine-tuning of the high IWC mask.

Finally, it has been suggested that apart from icing occurring within the cores of rapidly growing and/or mature convection - with potentially a lot of supercooled water - the majority of such events occurred in older/aged cirrus with 
large number densities. However, this is not a settled issue, although hopefully future field campaigns will enable a better characterization of the in-service icing conditions. The HAIC field campaigns in May 2015 (Cayenne, French Guiana, South America) and January 2016 (Darwin, northern Australia; Reunion, southwestern Indian Ocean) should provide more and better details of these conditions and will be used to further evaluate the MSG-CPP high IWC mask.

Data availability. Archived DARDAR data are available via ftp. icare.univ-lille1.fr; documentation can be found at http://www. icare.univ-lille1.fr/projects/dardar (ICARE Data and Services Center, 2014).

Archived RDT data are not publicly available and were made available on request by Meteo France (J. M. Moisselin, jeanmarc.moisselin@meteo.fr).

Archived MSG-CPP data can be accessed up to 3 years back via the 3-year rolling archive at http://msgcpp.knmi.nl (KNMI, 2015). For older data, contact KNMI.

The MSG-CPP High IWC mask is operationally available in near-real time at http://msgcpp.knmi.nl (KNMI, 2015) or http:// adaguc.knmi.nl (ADAGUC, 2015).

\section{The Supplement related to this article is available online at doi:10.5194/amt-10-1359-2017-supplement.}

Competing interests. The authors declare that they have no conflict of interest.

Acknowledgements. We thank the ICARE Data and Services Center for providing access to the DARDAR data used in this study.

Edited by: S. Malinowski

Reviewed by: two anonymous referees

\section{References}

Ackerman, A. S., Fridlind, A. M., Grandin, A., Dezitter, F., Weber, M., Strapp, J. W., and Korolev, A. V.: High ice water content at low radar reflectivity near deep convection - Part 2: Evaluation of microphysical pathways in updraft parcel simulations, Atmos. Chem. Phys., 15, 11729-11751, doi:10.5194/acp15-11729-2015, 2015.

ADAGUC (Atmospheric data access for the geospatial user community): available at: http://adaguc.knmi.nl/, last access: March 2015.

Anderson, G. P., Berk, A., Acharya, P. K., Matthew, M. W., Bernstein, L. S., Chetwynd Jr., J., Dothe, H., Adler-Golden, S. M., Ratkowski, A. J., Felde, G. W., Gardner, J. A., Hok, M. L., Richtsmeier, S. C., and Jeong, L. S.: Algorithms for Multispectral, Hyperspectral, and Ultraspectral Imagery VII, Proc. SPIE 4381, 455, doi:10.1117/12.437035, 2001.
Autonès, F.: Algorithm Theoretical Basis Document for "Rapid Development Thunderstorms" (RDT-PGE11 v2.3), SAF/NWC/CDOP/MFT/SCI/ATBD/11, available at: http:// www.nwcsaf.org/AemetWebContents/ScientificDocumentation/ Documentation/MSG/SAF-NWC-CDOP2-MFT-SCI-VR-11_ v3.0.pdf, 2012.

Bragg, M. B., Basar, T., Perkins, W. R., Selig, M. S., Voulgaris, P. G., Melody, J. W., and Sarter, N. B.: Smart icing systems for aircraft icing safety, AIAA Paper, 813, 2002.

Brown, P. R. A. and Francis, P. N.: Improved measurements of the ice water content in cirrus using a total-water probe, J. Atmos. Ocean. Tech., 12, 410-414, doi:10.1175/15200426(1995)012<0410:IMOTIW>2.0.CO;2, 2005.

Ceccaldi, M., Delanoë, J., Hogan, R. J., Pounder, N. L., Protat, A., and Pelon, J.: From CloudSat-CALIPSO to EarthCare: Evolution of the DARDAR cloud classification and its comparison to airborne radar-lidar observations, J. Geophys. Res.-Atmos., 118, 7962-7981, doi:10.1002/jgrd.50579, 2013.

Dee, D. P., Uppala, S. M., Simmons, A. J., Berrisford, P., Poli, P., Kobayashi, S., Andrae, U., Balmaseda, M. A., Balsamo, G., Bauer, P., Bechtold, P., Beljaars, A. C. M., van de Berg, L., Bidlot, J., Bormann, N., Delsol, C., Dragani, R., Fuentes, M., Geer, A. J., Haimberger, L., Healy, S. B., Hersbach, H., Hólm, E. V., Isaksen, L., Kållberg, P., Köhler, M., Matricardi, M., McNally, A. P., Monge-Sanz, B. M., Morcrette, J.-J., Park, B.-K., Peubey, C., de Rosnay, P., Tavolato, C., Thépaut, J.-N., and Vitart, F.: The ERA-Interim reanalysis: configuration and performance of the data assimilation system, Q. J. Roy. Meteorol. Soc., 137, 553597, doi:10.1002/qj.828, 2011.

Delanoë, J. and Hogan, R. J.: A variational scheme for retrieving ice cloud properties from combined radar, lidar, and infrared radiometer, J. Geophys. Res., 113, D07204, doi:10.1029/2007JD009000, 2008.

Delanoë, J. and Hogan, R. J.: Combined CloudSat-CALIPSOMODIS retrievals of the properties of ice clouds, J. Geophys. Res., 115, D00H29, doi:10.1029/2009JD012346, 2010.

Delanoë, J., Protat, A., Testud, J., Bouniol, D., Heymsfield, A. J., Bansemer, A., Brown, P. R. A., and Forbes, R. M.: Statistical properties of the normalized ice particle size distribution, J. Geophys. Res., 110, D10201, doi:10.1029/2004JD005405, 2005.

Delanoë, J., Heymsfield, A. J., Protat, A., Bansemer, A., and Hogan, R. J.: Normalized particle size distribution for remote sensing application, J. Geophys. Res.-Atmos.,119, 4204-4227, doi:10.1002/2013JD020700, 2014.

Francis, P. N., Hignett, P., and Macke, A.: The retrieval of cirrus cloud properties from aircraft multi-spectral reflectance measurements during EUCREX'93, Q. J. Roy. Meteorol. Soc., 124, 1273-1291, doi:10.1002/qj.49712454812, 1998.

Fridlind, A. M., Ackerman, A. S., Grandin, A., Dezitter, F., Weber, M., Strapp, J. W., Korolev, A. V., and Williams, C. R.: High ice water content at low radar reflectivity near deep convection - Part 1: Consistency of in situ and remote-sensing observations with stratiform rain column simulations, Atmos. Chem. Phys., 15, 11713-11728, doi:10.5194/acp-15-11713-2015, 2015.

Greuell, W., van Meijgaard, E., Clerbaux, N., and Meirink, J. F.: Evaluation of model-predicted top-of- atmosphere radiation and cloud parameters over Africa with observations from GERB and SEVIRI, J. Climate, 24, 4015-4036, doi:10.1175/2011JCLI3856.1, 2011. 
Grosvenor, D. P. and Wood, R.: The effect of solar zenith angle on MODIS cloud optical and microphysical retrievals within marine liquid water clouds, Atmos. Chem. Phys., 14, 7291-7321, doi:10.5194/acp-14-7291-2014, 2014.

Grzych, M. L. and Mason, J. G.: Weather Conditions Associated with Jet Engine Power-loss and Damage Due to Ingestion of Ice Particles: What We've Learned Through 2009, 14th Conference on Aviation, Range and Aerospace Meteorology, 2010.

Guillou, Y., Autonès, F., and Sénési, S.: Detection and monitoring of Convective clouds by satellite The Rapid Development Thunderstorm (RDT) product of the SAFNWC, extended abstract, Eumetsat Conference 2009, Bath, 21-25 September 2009, 2009.

Hess, M., Koelemeijer, R. B. A., and Stammes, P.: Scattering matrices of imperfect hexagonal ice crystals, J. Quant. Spectrosc. Ra., 60, 301-308, doi:10.1016/S0022-4073(98)00007-7, 1998.

ICARE Data and Services Center: Cloud-Aerosol-Water-Radiation Interactions, available at: http://www.icare.univ-lille1.fr/ projects/dardar, last access: November 2014.

KNMI: MSG Cloud Physical Properties (CPP), available at: http: //msgcpp.knmi.nl, last access: March 2015.

Mason, J. G., Strapp, J. W., and Chow, P.: The ice particle threat to engines in flight, 44th AIAA Aerospace Sciences Meeting (Vol. 4, 2445-2465), 2006.

McFarquhar, G. M. and Heymsfield, A. J.: The definition and significance of an effective radius for ice clouds, J. Atmos. Sci., 55, 2039-2052, doi:10.1175/15200469(1998)055<2039:TDASOA>2.0.CO;2, 1998.

Mecikalski, J. R., Feltz, W. F., Murray, J. J., Johnson, D. B., Bedka, K. M., Bedka, S. T., and Williams, E.: Aviation Applications for Satellite-Based Observations of Cloud Properties, Convection Initiation, In-Flight Icing, Turbulence, and Volcanic Ash, B. Am. Meteorol. Soc., 88, 1589, doi:10.1175/BAMS-88-10-1589, 2007.

Meirink, J. F.: Algorithm Theoretical Basis Document for Cloud Physical Products from SEVIRI, Tech. Rep. $\mathrm{SAF} / \mathrm{CM} / \mathrm{KNMI} / \mathrm{ATBD} / \mathrm{SEV} / \mathrm{CPP}$, Issue 1, Rev. 2, CM-SAF, 2013.

Mitchell, D. L., Lawson, R. P., and Baker, B.: Understanding effective diameter and its application to terrestrial radiation in ice clouds, Atmos. Chem. Phys., 11, 3417-3429, doi:10.5194/acp11-3417-2011, 2011.

Moody, E. G., King, M. D., Platnick, S., Schaaf, C. B., and Gao, F.: Spatially complete global spectral surface albedos: valueadded datasets derived from Terra MODIS land products, IEEE T. Geosci. Remote S., 43, 144-158, 2005.

Nakajima, T. and King, M. D.: Determination of the optical thickness and effective particle radius of clouds from reflected solar radiation measurements, part 1: Theory, J. Atmos. Sci., 47, 1878-1893, doi:10.1175/15200469(1990)047<1878:DOTOTA>2.0.CO;2, 1990.
Perkins, W. R., Sarter, N. B., Basar, T., Voulgaris, P. G., Gurbacki, H. M., Melody, J. W., and McCray, S. A.: An interdisciplinary approach to inflight aircraft icing safety (pp. 98-0095), AIAA, 1998.

Platnick, S.: Vertical photon transport in cloud remote sensing problems, J. Geophys. Res., 105, 22919-22935, doi:10.1029/2000JD900333, 2000.

Roebeling, R. A. and van Meijgaard, E.: Evaluation of the daylight cycle of model-predicted cloud amount and condensed water path over Europe with observations from MSG SEVIRI, J. Climate, 22, 1749-1766, doi:10.1175/2008JCLI2391.1, 2009.

Roebeling, R. A., Feijt, A. J., and Stammes, P.: Cloud property retrievals for climate monitoring: implications of differences between SEVIRI on METEOSAT-8 and AVHRR on NOAA-17, J. Geophys. Res., 111, D20210, doi:10.1029/2005JD006990, 2006.

Roebeling, R. A., Deneke, H. M., and Feijt, A. J.: Validation of cloud liquid water path retrievals from SEVIRI using one year of CloudNET observations, J. Appl. Meteorol. Clim., 47, 206-222, doi:10.1175/2007JAMC1661.1, 2008.

Stammes, P.: Spectral radiance modelling in the UV-Visible range, in: IRS 2000: Current problems in Atmospheric Radiation, edited by: Smith, W. L. and Timofeyev, Y. M., 385-388, A. Deepak, Hampton, VA, 2001.

Stephens, G.: Radiation profiles in extended water clouds, II: Parameterization schemes, J. Atmos. Sci., 35, 2123-2132, doi:10.1175/1520-0469(1978)035<2123:RPIEWC>2.0.CO;2, 1978.

Stephens, G. L., Vane, D. G., Boain, R. J., Mace, G. G., Sassen, K., Wang, Z., Illingworth, A. J., O’Connor, E. J., Rossow, W. B., Durden, S. L., Miller, S. D., Austin, R. T., Benedetti, A., Mitrescu, C., and CloudSat Science Team: The CloudSat mission and the A-Train: A new dimension of space-based observations of clouds and precipitation, B. Am. Meteorol. Soc., 83, 1771-1790, doi:10.1175/BAMS-83-12-1771, 2002.

Winker, D. M., Vaughan, M. A., Omar, A., Hu, Y., Powell, K. A., Liu, Z., Hunt, W. H., and Young, S. A. Overview of the CALIPSO mission and CALIOP data processing algorithms, J. Atmos. Oceanic Technol., 26, 2310-2323, doi:10.1175/2009JTECHA1281.1, 2009.

Wolters, E. L. A., Roebeling, R. A., and Feijt, A. J.: Evaluation of cloud-phase retrieval methods for SEVIRI on Meteosat-8 using ground-based lidar and cloud radar data, J. Appl. Meteorol. Clim., 47, 1723-1738, doi:10.1175/2007JAMC1591.1, 2008. 